\title{
Effect of surgical approaches on deltoid innervation and clinical outcomes in the treatment of proximal humeral fractures
}

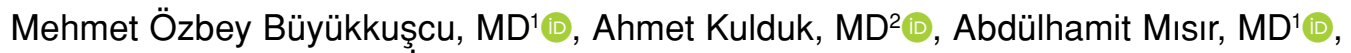

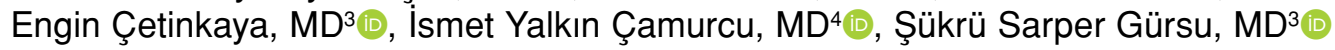 \\ 'Department of Orthopedics and Traumatology, Gaziosmanpaşa Training and Research Hospital, Istanbul, Turkey \\ 2Department of Orthopedics and Traumatology, Fenerbahçe Beko Basketball Team, Istanbul, Turkey \\ ${ }^{3}$ Department of Orthopedics and Traumatology, Health Science University, Baltalimanı Bone Diseases \\ Training and Research Hospital, Istanbul, Turkey \\ ${ }^{4}$ Department of Orthopedics and Traumatology, Faculty of Medicine, Erzincan University, Erzincan, Turkey
}

Proximal humeral fractures are common fractures that cause severe functional restrictions in the upper extremities. They are increasingly observed in the growing elderly population worldwide. In the advanced age group, they are the third most common fractures following those of the distal radius and hip. ${ }^{[1]}$ Although proximal humeral fractures are mostly treated conservatively, surgical treatment has gained popularity in recent years due to advances in implant technology with satisfactory clinical outcomes. ${ }^{[2-4]}$

The blood supply to the soft tissue covering the humeral head can be impaired during open

Received: February 13, 2020

Accepted: May 04, 2020

Published online: September 11, 2020

Correspondence: Mehmet Özbey Büyükkuşcu, MD.

Gaziosmanpaşa Eğitim ve Araștırma Hastanesi Ortopedi ve Travmatoloji Kliniği, 34255 Gaziosmanpaşa, İstanbul, Türkiye.

E-mail: o.z.b.e.y@hotmail.com

Doi: $10.5606 /$ ehc. 2020.74218

Citation: Büyükkuşcu MÖ, Kulduk A, Mısır A, Çetinkaya E, Çamurcu IY, Gürsu SS. Effect of surgical approaches on deltoid innervation and clinical outcomes in the treatment of proximal humeral fractures. Jt Dis Relat Surg 2020;31(3):516-522.

(2020 All right reserved by the Turkish Joint Diseases Foundation

This is an open access article under the terms of the Creative Commons Attribution-NonCommercial License, which permits use, distribution and reproduction in any medium, provided the original work is properly cited and is not used for commercial purposes (http://creativecommons.org/licenses/by-nc/4.0/).

\section{ABSTRACT}

Objectives: This study aims to investigate the effects of deltopectoral and anterolateral acromial approaches commonly used in open reduction-internal fixation of proximal humeral fractures on the clinical outcomes, and axillary nerve damage through electrophysiological assessment.

Patients and methods: Forty-eight patients ( 22 males, 26 females; mean age $47.9 \pm 13.2$ years; range, 22 to 73 years) diagnosed with Arbeitsgemeinschaft für Osteosynthesefragen (AO)/Orthopaedic Trauma Association (OTA) type 11 proximal humeral fractures who underwent osteosynthesis with anatomical locking plates in our hospital between January 2015 and June 2016 were prospectively examined. The patients were divided into two groups according to either the deltopectoral or anterolateral deltoid-split surgical approach used. Clinical outcomes were evaluated using the Disabilities of the Arm, Shoulder, and Hand (DASH) scores and Constant-Murley scores (CMS) obtained at three- and 12-month follow-up visits. Needle electromyography (EMG) was performed for the electrophysiological assessment of the deltoid muscle.

Results: There were no significant differences between the groups in terms of demographic data, follow-up times, and complications. DASH scores and CMS obtained postoperatively at three months $(\mathrm{p}=0.327$ and $\mathrm{p}=0.531$, respectively) and 12 months $(\mathrm{p}=0.324$ and $p=0.648$, respectively) revealed no significant differences. In addition, the two groups did not significantly differ with respect to the presence of EMG abnormalities $(\mathrm{p}=0.792)$. Avascular necrosis of the humeral head was detected in only two patients from the deltopectoral group.

Conclusion: Deltopectoral and anterolateral approaches do not differ regarding the presence of postoperative EMG abnormalities and functional outcomes. Surgeons can thus adopt either approach. However, dissection without damaging the soft tissue should be performed in both approaches.

Keywords: Approach, deltoid, electrophysiology, fracture, proximal humerus. 
reduction-internal fixation (ORIF). In addition, axillary nerve injury is an important concern in proximal humeral fracture surgery. In most studies, the incidence of axillary nerve injury was generally determined based on clinical examinations, but abnormal findings obtained from electrophysiological studies were higher than expected..$^{[5-8]}$ In this respect, the type of incision to be selected in proximal humeral fracture surgery remains controversial. In this study, we aimed to investigate the effects of deltopectoral and anterolateral acromial approaches commonly used in ORIF of proximal humeral fractures on the clinical outcomes, and axillary nerve damage through electrophysiological assessment.

\section{PATIENTS AND METHODS}

This prospective case-control study included patients who underwent osteosynthesis with proximal humeral anatomic locking plate (TST Orthopedics, Istanbul, Turkey) for Arbeitsgemeinschaft für Osteosynthesefragen (AO)/Orthopaedic Trauma Association (OTA) type 11 proximal humeral fractures $^{[3]}$ (56 patients) in Health Sciences University, Baltalimani Bone and Joint Diseases Training and Research Hospital between January 2015 and June 2016. The exclusion criteria were preoperative nerve deficit (one patient), open fracture, accompanying dislocation (two patients), pathological fracture, history of previous surgery, or fracture from the affected extremity. Patients who were lost to follow-up (five patients) were also excluded. Forty-eight patients (22 males, 26 females; mean age $47.9 \pm 13.2$ years; range, 22 to 73 years) in total participated in the study after exclusions. The study protocol was approved by the Health Sciences University, Baltalimani Bone and Joint Diseases Training and Research Hospital Ethics Committee (approval date and number: 19.01.2018/22). A written informed consent was obtained from each patient. The study was conducted in accordance with the principles of the Declaration of Helsinki.

Criteria for surgical acceptance included greater than $1 \mathrm{~cm}$ displacement, $45^{\circ}$ angulation, $2 \mathrm{~mm}$ intraarticular displacement, and medial metaphyseal column discontinuity at the anteroposterior and lateral transthoracic radiographs. ${ }^{[9]}$ In 16 patients, computed tomography was also performed.

All surgical procedures were performed within one week after trauma by four senior trauma surgeons. Patients were divided into two groups: the deltopectoral (group 1, n=27, 12 males, 15 females; mean age $48.2 \pm 14.4$ years; range, 22 to 73 years) and the anterolateral (group 2, $\mathrm{n}=21,10$ males, 11 females; mean age $47.3 \pm 11.5$ years; range, 31 to 71 years). Each individual surgeon determined which approach to use. In the presence of tuberculum majus comminution and/or posterior displacement of the tuberculum majus fragment, the anterolateral approach was preferred.

In the deltopectoral approach, a skin incision was performed from the coracoid process to the humeral shaft over the deltopectoral groove (Figure 1). The cephalic vein was found and laterally retracted. Meticulous soft tissue dissection was performed until the fracture site was exposed. After open reduction, temporal fixation was performed using Kirschner (K)-wires. The plate was then placed in the anterolateral region, 2-3 $\mathrm{mm}$ posterior to the bicipital groove and 5-10 $\mathrm{mm}$ distal to the greater tubercle.

In the anterolateral approach, a longitudinal skin incision was performed along the humeral shaft, approximately $5-7 \mathrm{~cm}$ distal from the anterolateral edge of the acromion. The anterior and middle fibers of the deltoid were separated approximately $2 \mathrm{~cm}$ distal from the corner of the acromion to reach the subacromial bursa, and the residual fragments of the subacromial bursa were excised (Figure 2). The axillary nerve was dissected and suspended. A space was created for the plate under the axillary nerve using a blunt periosteal elevator. After temporary fixation with K-wires using the same reduction technique described above, the plate was placed between the axillary nerve and the bone.

The postoperative physiotherapy program was performed under the supervision of a physiotherapist. Shoulder immobilization was achieved using a shoulder arm sling for two to three days. Subsequently, progressive passive shoulder range of motion and pendulum exercises were started. Active range of motion exercises were allowed at the fourth postoperative week. Strengthening exercises were started at the sixth postoperative week.

Follow-up examinations were performed at weeks two, four, and six, followed by months three, six, and 12. Functional evaluation of the patients was undertaken using the Constant-Murley score $(\mathrm{CMS})^{[0]}$ and the Disability of the Arm, Shoulder, and Hand (DASH) score at three and 12 months, postoperatively. ${ }^{[10]}$ Wound problems, infection, intraarticular screw penetration, avascular necrosis of the humeral head, and nonunion complications were recorded.

Electromyography (EMG) was performed by an experienced neurologist at three and 12 months postoperatively. As in routine EMG examinations, 

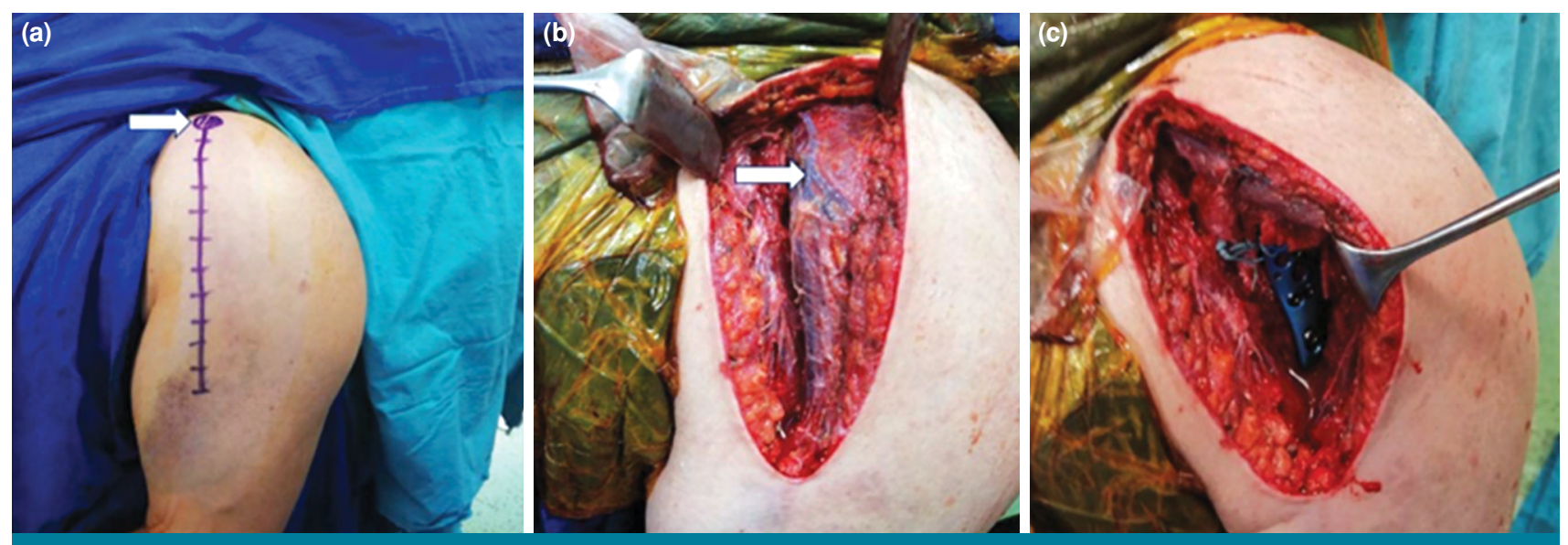

FIGURE 1. Deltopectoral approach. (a) Skin incision was performed extending from coracoid process (arrow) distally along humerus shaft. (b) Deltopectoral interval was dissected medially to cephalic vein (arrow). (c) Fracture was finally fixed with an anatomic locking plate using locking screws for humeral head and shaft.

the room temperature was maintained at an average of $25^{\circ} \mathrm{C}$ and skin temperature was maintained between $31^{\circ} \mathrm{C}$ and $34^{\circ} \mathrm{C}$. Bilateral needle electrodes (Neuropack MEB-9400, Nihon Kohden, Tokyo, Japan) were placed on two portions (anterior and posterior) of the deltoid muscle. Using these electrodes, the deltoid innervation of the axillary nerve within the surgical site was evaluated. The motor unit action potential morphology, pattern of recruitment, quantity of fibrillation potential, and maximal voluntary contraction patterns were recorded to score the status of denervation and reinnervation. ${ }^{[6]}$ All types of EMG abnormalities were recorded. All electrophysiological measurements were compared between the two groups, operative and nonoperative sides, and reference values.

\section{Statistical analysis}

IBM SPSS version 20.0 software (IBM Corp., Armonk, NY, USA) was used for the statistical analyses. Numerical data are presented as means and standard deviations, and categorical data are presented as frequencies and percentages. The means were compared using Student's t-test or MannWhitney U test according to the Kolmogorov-Smirnov analysis of normality. The Pearson chi-square test was used to compare frequencies, and $\mathrm{p}<0.05$ was considered statistically significant.

\section{RESULTS}

Patient demographics and the classifications of the fractures are shown in Table I. No significant
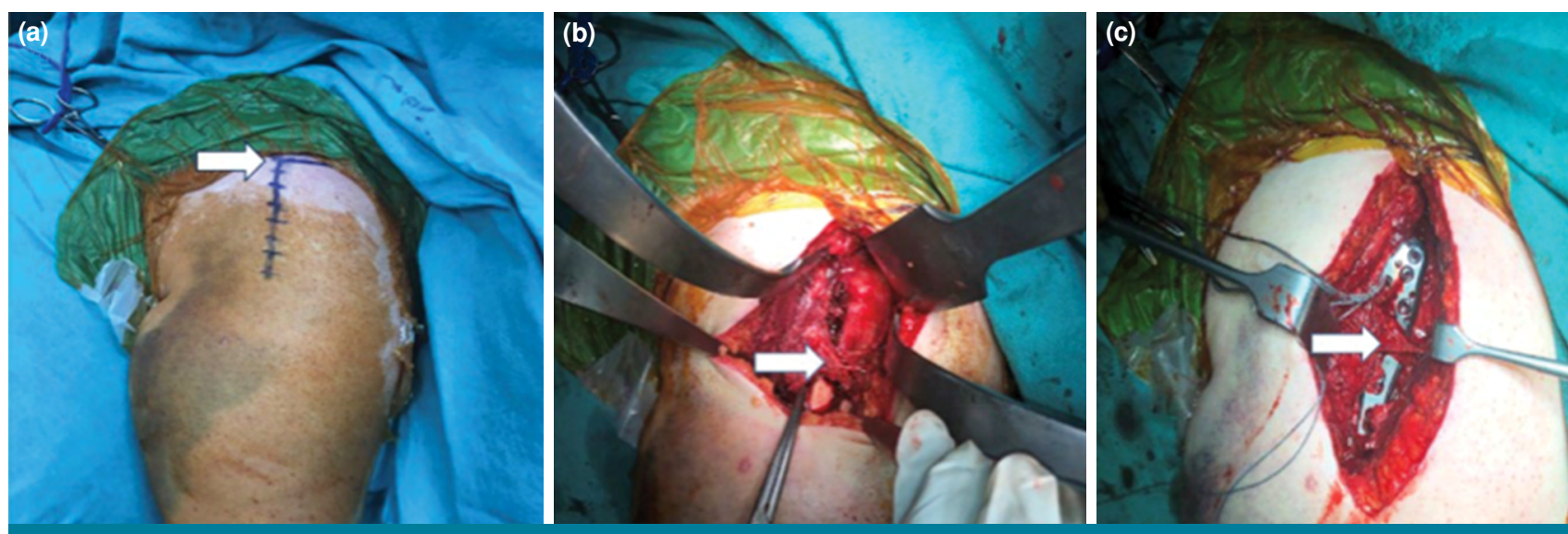

FIGURE 2. Anterolateral approach. (a) Skin incision was performed extending from palpable anterolateral edge of acromion (arrow) distally along fibers of deltoid muscle. (b) Dissection of deltoid muscle between pars clavicularis and pars acromialis with preservation of neurovascular bundle (arrow). (c) Final position of plate with locked head screws under axillary nerve (arrow) and deltoid muscle. 


\begin{tabular}{|c|c|c|c|c|c|c|c|}
\hline \multicolumn{8}{|c|}{$\begin{array}{c}\text { TABLE I } \\
\text { Demographic data of patient }\end{array}$} \\
\hline & \multicolumn{3}{|c|}{ Group $1(n=27)$} & \multicolumn{3}{|c|}{ Group $2(n=21)$} & \multirow[b]{2}{*}{$p$} \\
\hline & $\mathrm{n}$ & $\%$ & Mean \pm SD & $\mathrm{n}$ & $\%$ & Mean \pm SD & \\
\hline Age (year) & & & $48.2 \pm 14.4$ & & & $47.3 \pm 11.5$ & 0.799 \\
\hline \multicolumn{8}{|l|}{ Sex } \\
\hline Female & 12 & 44.4 & & 7 & 33.3 & & 0.555 \\
\hline Side of fracture (right) & 20 & 74.07 & & 13 & 61.9 & & 0.531 \\
\hline Type of fracture & & & & & & & 0.097 \\
\hline A & 8 & & & 11 & & & \\
\hline B & 17 & & & 9 & & & \\
\hline$C$ & 2 & & & 1 & & & \\
\hline Follow-up time (month) & & & $16.3 \pm 2.7$ & & & $18.1 \pm 4.6$ & 0.113 \\
\hline
\end{tabular}

difference was found between the groups in terms of age, sex, fracture side, and fracture type (Table I).

There was no significant difference in CMS between the two groups at months three $(p=0.531)$ and $12(p=0.648)$ postoperatively, respectively. Similarly, no significant difference was found in the DASH scores between the two groups in the follow-ups at months three and $12(\mathrm{p}=0.327$ and $\mathrm{p}=0.324$, respectively) (Table II).

Electromyography abnormalities were detected in 10 of the $48(20.83 \%)$ patients in electrophysiological evaluation at month three postoperatively. According to the electrophysiological assessment at month three, $22.2 \%$ of the patients in group 1 and $19.04 \%$ of those in group 2 had EMG abnormalities. Five reinnervation changes and one denervation change were found in group 1. Two reinnervation changes, and two denervation changes were found in group 2. At the postoperative $12^{\text {th }}$-month follow-up, four (8.3\%) patients were found to have persistent EMG abnormalities. Deltoid muscle electrophysiological abnormalities were observed in $7.4 \%$ and $9.4 \%$ of the patients in groups 1 and 2, respectively. Two reinnervation changes were observed in group 1 . One reinnervation change, and one denervation change were observed in group 2. None of the cases with EMG abnormalities had functional deficits. There was no significant difference in terms of EMG abnormalities between groups 1 and 2 in months three and 12, postoperatively ( $p=0.788$ and $p=0.792$, respectively) (Table II).

In group 1 , one $(3.7 \%)$ patient had a superficial infection, one $(3.7 \%)$ had nonunion, and two (7.4\%) developed avascular necrosis. In group 2, avascular necrosis $(4.76 \%)$, inadequate reduction $(4.76 \%)$, and intra-articular screw penetration $(4.76 \%)$ were recorded in one patient each. The superficial infection was treated with oral antibiotics. There were no

\begin{tabular}{|c|c|c|c|c|c|c|c|}
\hline Clini & nd $\epsilon$ & ctroph & $\begin{array}{l}\text { 3LE II } \\
\text { ological find }\end{array}$ & of & tients & & \\
\hline & & Group & $n=27)$ & & Group & $n=21)$ & \\
\hline & $\mathrm{n}$ & $\%$ & Mean $\pm S D$ & $\mathrm{n}$ & $\%$ & Mean $\pm S D$ & $p$ \\
\hline CMS (month 3) & & & $56.4 \pm 15.9$ & & & $59.0 \pm 12.2$ & 0.531 \\
\hline CMS (month 12) & & & $76.4 \pm 9.3$ & & & $77.5 \pm 7.6$ & 0.648 \\
\hline DASH score (month 3) & & & $25.1 \pm 10.8$ & & & $22.2 \pm 9.8$ & 0.327 \\
\hline DASH score (month 12) & & & $13.2 \pm 6.6$ & & & $11.6 \pm 4.2$ & 0.324 \\
\hline EMG abnormalities (month 3) & 6 & 22.2 & & 4 & 19.04 & & 0.788 \\
\hline EMG abnormalities (month 12) & 2 & 7.4 & & 2 & 9.5 & & 0.792 \\
\hline Complications & 4 & 14.8 & & 3 & 14.2 & & 0.741 \\
\hline
\end{tabular}


significant differences between the two groups in terms of complications $(\mathrm{p}=0.741)$ (Table II).

\section{DISCUSSION}

The most important finding of our study was that there was no significant difference between the deltopectoral and anterolateral approaches with respect to clinical outcomes and deltoid muscle innervation, in patients who underwent ORIF for proximal humeral fractures.

In the treatment of displaced proximal humeral fractures, many surgeons prefer the deltopectoral approach because of the low risk of axillary nerve damage. However, the literature does not support this hypothesis, with the incidence of nerve injuries ranging from $0 \%$ to $42 \%$ for the deltopectoral approach and from 6 to $33 \%$ for the anterolateral approach. ${ }^{[4-6,11,12]}$ Deltopectoral approach has some disadvantages. These disadvantages are additional soft tissue damage and retraction of the deltoid muscle with potential soft tissue stripping. Also, obtaining lateral to medial drilling is difficult. Partial release of the deltoid insertion and retraction of the anterior one third fibers are sometimes needed. However, it may lead to functional deficit in the deltoid muscle. ${ }^{[13,14]}$ The anterolateral acromial approach involves splitting the deltoid muscle, and denervation of the deltoid, due to posterior origin of the innervation of the deltoid muscle, may occur. In the anterolateral acromial approach, only the anterior branch of the axillary nerve, and subsequently the anterior part of the deltoid, is at risk. ${ }^{[15,16]}$ In our study, we found deltoid innervation abnormalities in $22.2 \%$ and $19.0 \%$ of patients using the deltopectoral and anterolateral approaches, respectively, at the third postoperative follow-up, and $7.4 \%$ and $9.4 \%$ at the $12^{\text {th }}$ postoperative follow-up, respectively. According to our results, deltoid innervation abnormalities with either the deltopectoral or anterolateral approaches do not seem to be different. In the presence of posterior displacement of the tuberculum majus fragment, the risk of deltoid dysfunction and axillary nerve damage may be reduced using anterolateral approach. Also, in anterolateral acromial approach, the neurovascular bundle including the anterior branch of the axillary nerve is mobilized to improve the fracture site exposure and to perform the plate fixation. As the dissection itself may increase the risk of neural injury, the neurovascular bundle may be isolated along with the adjacent soft tissues without dissection.

In the literature, many studies have aimed to demonstrate the risk of axillary nerve injury in the fixation of proximal humeral fractures using physical examinations. Only a few studies have performed postoperative electrophysiological evaluations. $\mathrm{Wu}$ et al. ${ }^{[14]}$ compared the electrophysiological results between 28 patients treated via the deltoidsplit approach and 32 patients treated via the deltopectoral approach. Axillary nerve EMG and electroneurography tests were performed in both groups at three months postoperatively. In four patients $(12.5 \%)$ in the deltopectoral group and seven patients $(25 \%)$ in the deltoid-split group, findings indicated reinnervation or denervation of the deltoid muscle. However, none of the patients had any clinical abnormalities. ${ }^{[14]}$ In a study of 23 patients treated with the minimal anterolateral acromial approach for proximal humeral fractures, Röderer et al. ${ }^{[16]}$ classified the EMG changes showing an axillary nerve lesion or direct muscle trauma as acute, chronic, and combined and characterized them semi-quantitatively as mild, moderate, and severe. The patients were clinically evaluated, and three patients were found to have a partial axillary nerve lesion with functional loss. Although subclinical EMG findings were frequently observed, the rate of functional loss was less common. Two limitations of that study were that only a few patients received follow-up, and not all the patients in the study underwent electrophysiological evaluation. ${ }^{[16]}$ In their study, Westphal et al. ${ }^{[17]}$ reported a permanent axillary nerve lesion in $10 \%$ of proximal humeral fracture patients who underwent ORIF using the deltoid-split approach. However, there was no correlation between electrophysiological evaluations and clinical outcomes. Nevertheless, electrophysiological evaluations were reported to be more suitable for the detection of axillary nerve injuries. ${ }^{[17]}$ In their prospective study, Gavaskar et al. ${ }^{[18]}$ examined 50 patients with proximal humeral fractures who underwent ORIF using the extended deltoid-split approach. Electrophysiological findings showed three temporary and one permanent axillary nerve lesion. Permanent nerve lesions did not show any correlation with clinical findings because no sensation or motor deficits were observed in patients with EMG anomalies. ${ }^{[18]}$ In the current study, we detected postoperative EMG abnormalities in 10 out of 48 patients $(20.8 \%$; six deltopectoral and four anterolateral) at the third month follow-up. When they were re-evaluated at the $12^{\text {th }}$ month follow-up, EMG abnormalities were observed in four patients (12.5\%; two deltopectoral and two anterolateral). Additionally, no significant difference was found in the comparison of functional outcome scores between the deltopectoral and anterolateral approach groups. According to our results, most of the EMG abnormalities improved in the first postoperative 
year, and EMG abnormalities and functional outcome scores were not affected by the surgical approach. In addition, EMG abnormalities have been reported in up to $62 \%$ of patients with shoulder trauma. However, the needle EMG test is the best-known diagnostic test for iatrogenic nerve injuries. ${ }^{[15,17]}$ In many patients with axillary nerve damage, it is observed that only deltoid anterior fibers are affected ${ }^{[17]}$ In these patients, the deficit may not give any clinical signs due to compensation by the middle and posterior deltoid fibers.

In proximal humeral fracture surgery, dissection of soft tissue and manipulation of fractured bone shards result in vascular damage. This increases the risk of avascular necrosis. ${ }^{[9,19]}$ In the deltopectoral approach, the anterolateral branch of the anterior humeral circumflex artery, providing primary blood supply to the proximal humerus, can be damaged when exposing the tendon in the bicipital groove. This compromises the blood supply to the humeral head and increases the risk of avascular necrosis. Studies using the deltopectoral approach to perform locking plate fixation on proximal humeral fractures reported avascular necrosis rates between $4 \%$ and $16 \% \cdot{ }^{[19,20]}$ Considering this increased possibility of damage to the anterior humeral circumflex artery, which has an important function in supplying blood to the humeral head, some researchers recommended the use of an anterolateral acromial incision, rather than the deltopectoral approach. ${ }^{[2,22]}$ In our study, consistent with the literature, we observed humeral head avascular necrosis in two patients who underwent the deltopectoral approach.

There are several limitations to this study. The main limitation was that isometric deltoid muscle strength was not evaluated. It was therefore impossible to evaluate the clinical reflections of EMG findings. Second, we evaluated a relatively small number of patient groups. Future studies including a higher number of patients would provide more detailed data. Third, preoperative EMG evaluation was not performed. Therefore, it is difficult to differentiate the traumatic and iatrogenic nerve injuries. Further studies evaluating electrophysiological abnormalities of the deltoid muscle in each fracture type with larger numbers of participants are needed.

In conclusion, deltopectoral and anterolateral approaches do not differ with respect to the presence of postoperative EMG abnormalities and functional outcomes. Surgeons can adopt either approach, but dissection without damaging the soft tissue should be performed in both approaches.
Further randomized controlled prospective studies with larger sample sizes are needed to determine the effect of EMG abnormalities on clinical and functional outcomes.

\section{Declaration of conflicting interests}

The authors declared no conflicts of interest with respect to the authorship and/or publication of this article.

\section{Funding}

The authors received no financial support for the research and/or authorship of this article.

\section{REFERENCES}

1. Bozkurt HH, Atik OŞ, Tokgöz MA. Can distal radius or vertebra fractures due to low-energy trauma be a harbinger of a hip fracture? Eklem Hastalik Cerrahisi 2018;29:100-3.

2. Korkmaz MF, Aksu N, Gögüuş A, Debre M, Kara AN, Işiklar ZU. The results of internal fixation of proximal humeral fractures with the PHILOS locking plate. Acta Orthop Traumatol Turc 2008;42:97-105.

3. Wang H, Rui B, Lu S, Luo C, Chen Y, Chai Y. Locking plate use with or without strut support for varus displaced proximal humeral fractures in elderly patients. JB JS Open Access 2019;4:e0060.1-8.

4. Esen E, Doğramaci $Y$, Kömürcü M, Kanatli U, Bölükbaşi S, Atahan AO. Biomechanical comparison of fixation of twopart osteoporotic neck fracture of the proximal humerus using uni-planar and multi-planar Kirschner wire. Eklem Hastalik Cerrahisi 2009;20:114-8.

5. Khan LA, Robinson CM, Will E, Whittaker R. Assessment of axillary nerve function and functional outcome after fixation of complex proximal humeral fractures using the extended deltoid-splitting approach. Injury 2009;40:181-5.

6. Knežević J, Mihalj M, Čukelj F, Ivanišević A. MIPO of proximal humerus fractures through an anterolateral acromial approach. Is the axillary nerve at risk? Injury 2017;48 Suppl 5:S15-S20.

7. Traver JL, Guzman MA, Cannada LK, Kaar SG. Is the axillary nerve at risk during a deltoid-splitting approach for proximal humerus fractures? J Orthop Trauma 2016;30:240-4.

8. Robinson CM, Stirling PHC, Goudie EB, MacDonald DJ, Strelzow JA. Complications and long-term outcomes of open reduction and plate fixation of proximal humeral fractures. J Bone Joint Surg [Am] 2019;101:2129-39.

9. Peters PM, Plachel F, Danzinger V, Novi M, Märdian S, Scheibel $M$, et al. Clinical and radiographic outcomes after surgical treatment of proximal humeral fractures with head-split component. J Bone Joint Surg [Am] 2020;102:68-75.

10. Ye T, Wang L, Zhuang C, Wang Y, Zhang W, Qiu S. Functional outcomes following locking plate fixation of complex proximal humeral fractures. Orthopedics 2013;36:e715-22.

11. Lädermann A, Lübbeke A, Mélis B, Stern R, Christofilopoulos P, Bacle G, et al. Prevalence of neurologic lesions after total shoulder arthroplasty. J Bone Joint Surg [Am] 2011;93:1288-93.

12. Nagda SH, Rogers KJ, Sestokas AK, Getz CL, Ramsey ML, Glaser DL, et al. Neer Award 2005: Peripheral nerve function during shoulder arthroplasty using intraoperative nerve monitoring. J Shoulder Elbow Surg 2007;16(3 Suppl):S2-8. 
13. Clavert P, Adam P, Bevort A, Bonnomet F, Kempf JF. Pitfalls and complications with locking plate for proximal humerus fracture. J Shoulder Elbow Surg 2010;19:489-94.

14. Wu CH, Ma CH, Yeh JJ, Yen CY, Yu SW, Tu YK. Locked plating for proximal humeral fractures: differences between the deltopectoral and deltoid-splitting approaches. J Trauma 2011;71:1364-70.

15. Visser CP, Tavy DL, Coene LN, Brand R. Electromyographic findings in shoulder dislocations and fractures of the proximal humerus: comparison with clinical neurological examination. Clin Neurol Neurosurg 1999;101:86-91.

16. Röderer G, Sperfeld AD, Hansen P, Krischak G, Gebhard F, Kassubek J. Electrophysiological assessment of the deltoid muscle after minimally invasive treatment of proximal humerus fractures - a clinical observation. Open Orthop J 2011;5:223-8.

17. Westphal T, Woischnik S, Adolf D, Feistner H, Piatek S. Axillary nerve lesions after open reduction and internal fixation of proximal humeral fractures through an extended lateral deltoid-split approach: electrophysiological findings.
J Shoulder Elbow Surg. 2017;26:464-71.

18. Gavaskar AS, Chowdary N, Abraham S. Complex proximal humerus fractures treated with locked plating utilizing an extended deltoid split approach with a shoulder strap incision. J Orthop Trauma 2013;27:73-6.

19. Sakoma Y, Hirooka T. Relationship between the axillary nerve and accompanying vessels and proximal humeral locking plates in Japanese: An MRI Study. Acta Med Okayama 2017;71:525-9.

20. Hente R, Kampshoff J, Kinner B, Füchtmeier B, Nerlich M. Treatment of dislocated 3- and 4-part fractures of the proximal humerus with an angle-stabilizing fixation plate. Unfallchirurg 2004;107:769-82.

21. Gardner MJ, Voos JE, Wanich T, Helfet DL, Lorich DG. Vascular implications of minimally invasive plating of proximal humerus fractures. J Orthop Trauma 2006;20:602-7.

22. Hepp P, Theopold J, Voigt C, Engel T, Josten C, Lill H. The surgical approach for locking plate osteosynthesis of displaced proximal humeral fractures influences the functional outcome. J Shoulder Elbow Surg 2008;17:21-8. 